\author{
Short note
}

\title{
RF cloning: A restriction-free method for inserting target genes into plasmids
}

\author{
Fusinita van den Ent ${ }^{*}$, Jan Löwe \\ MRC Laboratory of Molecular Biology, Hills Road, Cambridge CB2 2QH, UK
}

Received 13 September 2005; accepted 22 December 2005

\begin{abstract}
Restriction-free (RF) cloning provides a simple, universal method to precisely insert a DNA fragment into any desired location within a circular plasmid, independent of restriction sites, ligation, or alterations in either the vector or the gene of interest. The technique uses a PCR fragment encoding a gene of interest as a pair of primers in a linear amplification reaction around a circular plasmid. In contrast to QuickChange ${ }^{\mathrm{TM}}$ site-directed mutagenesis, which introduces single mutations or small insertions/deletions, RF cloning inserts complete genes without the introduction of unwanted extra residues. The absence of any alterations to the protein as well as the simplicity of both the primer design and the procedure itself makes it suitable for high-throughput expression and ideal for structural genomics.

Crown Copyright (C) 2006 Published by Elsevier B.V. All rights reserved.
\end{abstract}

Keywords: Restriction-free cloning; Structural genomics; High-throughput cloning; Ligation independent cloning

\section{Introduction}

High-throughput crystallisation would benefit from a straightforward cloning procedure that is amenable to automation. Restriction-free cloning facilitates a simple primer design and provides a less labour-intensive approach for making expression constructs than commonly used. Conventional cloning techniques rely on enzymatic digestion of the insert and the vector before a clone can be obtained. Hence, one often encounters limitations in choice of cloning strategy because of the lack of suitable restriction sites or is hampered by the multiplicity of restriction sites in the DNA. For restriction site-dependent cloning the efficiency of obtaining

* Corresponding author. Tel.: +44 1223 252969; fax: +44 1223213556.

E-mail address: fent@mrc-lmb.cam.ac.uk (F. van den Ent). 
positive clones is directly correlated to the effectiveness of the restriction digests. To circumvent these limitations, different approaches have been taken to enhance cloning efficiency, such as positive selection, in which only colonies containing plasmids with inserts survive or discrimination on the basis of blue/white screening. Alternative methods, including Gateway ${ }^{\circledR}$ technology (Invitrogen), heterostagger cloning [1], TA cloning [2], the use of uracil DNA glycosylase [3], or ligation-independent cloning [4,5] avoid treating the insert with restriction enzymes. However, these methods need special vectors, which are labour intensive and often introduce extra residues in the final product, which may not be desirable. The heterostagger cloning technique uses an insert with sticky ends that are generated by mixing two different lengths PCR products created with two different primer pairs. Only one quarter of the mixture will have complementary ends that can be ligated into a vector prepared with the appropriate restriction enzymes [1]. TA-cloning uses the terminal transferase activity of certain polymerases such as Taq polymerase, which adds an extra $3^{\prime} \mathrm{A}$ at both ends of the PCR product. The PCR product is then ligated into a specially treated linearized vector with a $5^{\prime} \mathrm{T}$ overhang. A different way of producing sticky ends in an insert is by incorporating dUMP's near the $5^{\prime}$ ends of both primers. The PCR product is treated with uracil DNA glycosylase leading to degradation of the $5^{\prime}$ ends of the insert. The newly generated $3^{\prime}$ overhangs can be much longer than those created by most restriction enzymes which enables the formation of a more stable DNA complex upon annealing and which can directly be transformed without the need of in vitro ligation [3]. A variation of this method is ligation-independent cloning (LIC), which creates relatively long cohesive ends by an exonuclease [6]. Although the above methods have made cloning more accessible for cases where conventional restriction site cloning was impossible, they all need special vectors and are often labour intensive.

The restriction-free (RF) cloning strategy described here is ligation and restriction siteindependent and is widely applicable to any circular vector. This flexibility in choice of vector and insert makes it exceptionally suitable for high-throughput cloning. Especially in structural genomics additional amino acids are undesirable, but are often unavoidable in conventional cloning. For RF cloning there is no need for introducing any extra basepairs. It basically is a modified QuickChange ${ }^{\mathrm{TM}}$ reaction (Stratagene, La Jolla, CA) in which a gene rather than a mutation is inserted into a vector. The gene of interest is amplified in a regular PCR, which produces a primer pair that, once annealed to the vector of interest, is extended in a linear amplification reaction. The parental plasmid is digested by DpnI, cleaving methylated DNA. Average yields obtained with the current method are about $90 \%$. The total size of insert and vector is limited to $15 \mathrm{kbp}$, although longer constructs can be made at a lower efficiency.

\section{Materials and methods}

\section{1. $P C R$}

All genes of interest were amplified from genomic DNA (purchased from ATCC) using KOD hot start DNA polymerase (Novagen) according to the manufacturers' instructions. Typically, primers were about 50 bases long and were HPLC purified (Operon). The forward primer had a 24 base overlap with the vector which was complementary to the $5^{\prime}$ end of the desired point of insertion, followed by a start codon and $20-25$ bases of the $5^{\prime}$ end of the gene of interest. The reverse primer annealed to the vector with 24 bases complementary to the $3^{\prime}$ end of the point of insertion. Amplification reactions were performed in a total volume of $100 \mu$. The PCR products 
were checked on an agarose gel and purified using a PCR purification kit (Qiagen). The final concentration of the PCR was diluted down to $100 \mathrm{ng} / \mu \mathrm{l}$.

\subsection{Linear amplification reaction}

2-20 nM of PCR product was used in a linear amplification reaction with 6-400 pM of pHis 17 (B. Miroux personal communication), $200 \mu \mathrm{M}$ dNTP's (Roche), $1 \times$ reaction buffer, 2.5 units PfuTurbo ${ }^{\mathrm{TM}}$ (Stratagene) in a total volume of $50 \mu \mathrm{l}$. The mixture was heated for $30 \mathrm{~s}$ at $95{ }^{\circ} \mathrm{C}$, followed by 35 cycles consisting of denaturation at $95{ }^{\circ} \mathrm{C}(30 \mathrm{~s})$, annealing at $55{ }^{\circ} \mathrm{C}(1$ min) and elongation at $68{ }^{\circ} \mathrm{C}(2 \mathrm{~min}$ per $\mathrm{kb}$ of new construct). Once complete, $9 \mu \mathrm{l}$ of the reaction were treated with $1 \mu \mathrm{DpnI}$ for $2 \mathrm{~h}$ at $37{ }^{\circ} \mathrm{C}$ to digest the methylated parental plasmid. The reaction mix was then transformed into electrocompetent TG1 cells [7]. Positive clones were confirmed by DNA sequencing.

\subsection{Protein expression}

All constructs were designed to have a C-terminal $6 *$ His-tag to facilitate purification. Test expressions were performed using either C41 [8] or BL21AI cells (Invitrogen), which were induced in early log phase with $1 \mathrm{mM}$ IPTG or $0.2 \%$ arabinose, respectively. After $4 \mathrm{~h}$ at $37{ }^{\circ} \mathrm{C}$, $10 \mathrm{ml}$ of the cells were harvested, frozen and lysed in $600 \mu \mathrm{l}$ of cold lysis buffer $(50 \mathrm{mM}$ Tris, $300 \mathrm{mM} \mathrm{NaCl}, 20 \mathrm{mM}$ imidazole, $\mathrm{pH}$ 8.0) in the presence of lysozyme and DNaseI (Sigma). The cells were opened by sonication, and cell debris was pelleted for $7 \mathrm{~min}$ at $14 \mathrm{krpm}$, at $4{ }^{\circ} \mathrm{C}$. The supernatant was bound to a $\mathrm{Ni}^{2+}$-NTA spin column (Qiagen), which was subsequently washed 3 times with $600 \mu \mathrm{l}$ cold lysis buffer and eluted in $200 \mu \mathrm{l}$ elution buffer $(50 \mathrm{mM}$ Tris, $600 \mathrm{mM}$ imidazole, $\mathrm{pH}$ 7.0). To discriminate between protein insolubility and absence of expression, a $\mathrm{Ni}^{2+}$-NTA spin column was used with the same buffers supplemented with $8 \mathrm{M}$ urea.

\section{Results and discussion}

Restriction free (RF) cloning is inspired by oligonucleotide-directed mutagenesis (QuickChange $^{\mathrm{TM}}$, Stratagene). This method uses short mutagenic oligonucleotides that incorporate one or a few substitutions, short insertions or deletions. The introduction of larger insertions of up to $1.1 \mathrm{~kb}$ has been demonstrated before as being a possibility by Geiser et al. [9]. A PCR product encoding the gene of interest is used as a primer pair in a linear amplification reaction with any chosen vector as a template. The PCR product has unique priming sites at either end, which are complementary to sequences flanking the site of insertion in the vector (Fig. 1). The gene of interest is incorporated into the vector using high fidelity PfuTurbo ${ }^{\text {тм }}$ DNA polymerase (Stratagene) that extends the primer over the entire length of the plasmid, as in sitedirected mutagenesis (QuickChange ${ }^{\mathrm{TM}}$, Stratagene). Subsequently, the parental vector, which was isolated from a Dam methylase ${ }^{+}\left(\mathrm{dam}^{+}\right)$E. coli strain, is digested by DpnI and the mixture is transformed into electrocompetent $E$. coli cells. Colonies are screened for the presence of the gene of interest by PCR (with one primer in the vector and one primer in the gene) or by using diagnostic restriction enzyme digestion. Positive clones should be confirmed by sequencing.

We made over twenty constructs to demonstrate the power of the method with inserts and templates of variable size (Table 1). The plasmid used in this study is designed for protein expression with the gene under the control of a $\mathrm{T} 7$ promoter and a C-terminal $\mathrm{His}_{6}$-tag to facilitate protein purification. Since the method does not rely on restriction enzymes or special 


\section{1: Vector prep and PCR}

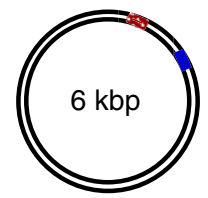

$\underset{50 \mathrm{bp}}{\stackrel{\text { F-primer }}{\longrightarrow}}$

\section{2: Linear amplification}
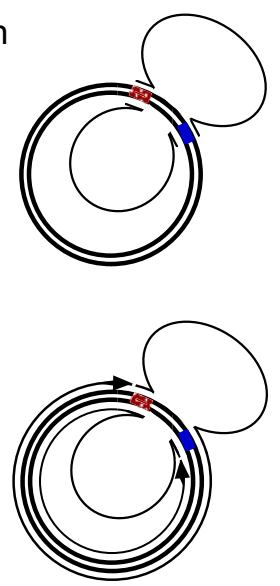

\section{3: Dpnl digestion}

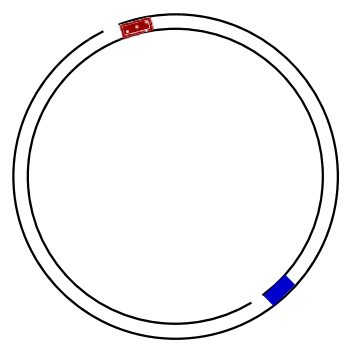

Fig. 1. Schematic representation of restriction-free (RF) cloning. 1. A circular vector isolated from a $\operatorname{dam}^{+}$strain has unique priming sites (depicted in red and blue) and is combined with a PCR product encoding the gene of interest flanked by priming sites complementary to those in the vector. 2 . The PCR product acts as a primer pair in a linear amplification reaction. Once annealed to the vector, PfuTurbo ${ }^{\text {тм }}$ extends and incorporates the gene into a nicked, circular DNA molecule. 3. The parental vector is digested with DpnI and the double nicked, circular, double-stranded DNA is transformed into a suitable host cell. (For interpretation of the references to colour in this figure legend, the reader is referred to the web version of this article.)

treatments, any circular vector can be used as long as it is propagated in a $\mathrm{dam}^{+}$E. coli strain. As shown in Fig. 1, the insertion of the gene of interest occurs simultaneously with a deletion of the stretch of DNA that is flanked by the annealing sequences of the primers. The efficiency of the 
Table 1

\begin{tabular}{|c|c|c|c|c|c|c|c|c|}
\hline Construct & $\begin{array}{l}\text { Template } \\
(\mathrm{pM})\end{array}$ & $\begin{array}{l}\text { PCR } \\
(\mathrm{nM})\end{array}$ & $\begin{array}{l}\text { Length } \\
(\mathrm{kb})\end{array}$ & $\begin{array}{l}\text { Plasmid } \\
(\mathrm{kb})\end{array}$ & $\begin{array}{l}\text { Positive } \\
\text { miniprep }\end{array}$ & $\begin{array}{l}\text { Sequence } \\
\text { (all } \mathrm{F} \text { and } \mathrm{B} \text { ) }\end{array}$ & Protein & Xtals \\
\hline $\mathrm{BSC}$ & 280 & 8.4 & 0.87 & 3.5 & $3 / 6$ & $\mathrm{OK}$ & No & - \\
\hline BSC1 & 60 & 8.8 & 0.82 & 3.4 & $1 / 1$ & 2 mut. in $\mathrm{F}$ primer & No & - \\
\hline BSC2 & 60 & 9.1 & 0.80 & 3.4 & $6 / 6$ & $\mathrm{OK}$ & Yes & Yes \\
\hline BSC3 & $6-60$ & 10 & 0.73 & 3.3 & $4 / 5$ & $\mathrm{OK}$ & Yes & Yes \\
\hline $\mathrm{ECC}$ & 56 & 6.6 & 1.1 & 3.7 & $3 / 5$ & $\mathrm{OK}$ & No & - \\
\hline ECC1 & 60 & 7.2 & 1.0 & 3.6 & $6 / 6$ & Mut. in $\mathrm{F}$ primer & No & - \\
\hline $\mathrm{ECC} 2$ & 60 & 7.2 & 1.0 & 3.6 & $1 / 1$ & $\mathrm{OK}$ & Yes & No \\
\hline ECC3 & $6-60$ & 7.6 & 0.95 & 3.5 & $5 / 5$ & $\mathrm{OK}$ & Yes & Yes \\
\hline LMFCCC & 400 & 12 & 0.50 & 4.4 & $1 / 1$ & $\mathrm{OK}$ & Yes & No \\
\hline CCCLMF & 40 & 11.6 & 0.52 & 4.3 & $6 / 6$ & $\mathrm{OK}$ & Yes & Yes \\
\hline TTQ & 40 & 10.8 & 0.56 & 3.1 & $1 / 1$ & $\mathrm{OK}$ & No & - \\
\hline CCQ & 200 & $8-16$ & 0.75 & 3.3 & $2 / 4$ & $\mathrm{OK}$ & No & - \\
\hline CDQ & 60 & 9.8 & 0.62 & 3.2 & $3 / 3$ & $\mathrm{OK}$ & Yes & Yes \\
\hline LMQ & 200 & $9-18$ & 0.68 & 3.3 & $6 / 6$ & Mut. in $\mathrm{F}$ primer & No & - \\
\hline SEQ & 60 & 8.6 & 0.70 & 3.3 & $1 / 1$ & $\mathrm{OK}$ & Yes & No \\
\hline SAQ & 60 & 7.8 & 0.78 & 3.3 & $3 / 3$ & $\mathrm{OK}$ & Yes & nd \\
\hline CRC & 60 & 6.2 & 0.97 & 3.5 & $1 / 1$ & $\mathrm{OK}$ & Yes & nd \\
\hline LMC & 60 & 7.6 & 0.79 & 3.3 & $1 / 1$ & $\mathrm{OK}$ & Yes & Yes \\
\hline TCF1 & 200 & $3-6$ & 2.0 & 4.6 & $4 / 4$ & $\mathrm{OK}$ & Yes & nd \\
\hline TCF2 & 200 & $3-6$ & 2.0 & 4.6 & $4 / 4$ & $\mathrm{OK}$ & Yes & nd \\
\hline TMSMC & 140 & 1.7 & 3.5 & 6.1 & $5 / 9$ & $\mathrm{OK}$ & No & - \\
\hline BSSMC & 187 & 6.8 & 3.5 & 6.1 & $1 / 12$ & $\mathrm{OK}$ & Yes & nd \\
\hline
\end{tabular}

reaction is not significantly affected by the length of the deletions. Deletions in the parental plasmid of as little as 273 basepairs to as many as $2.4 \mathrm{kbp}$ showed no difference, thus providing a glimpse of the wide choice in vectors that can be used as a template. The genes cloned varied between 0.5 and $3.5 \mathrm{kbp}$ (Table 1). The efficiency is about $90 \%$ on average. Sequencing revealed that all cloned genes were correct, except for a few cases where the primers introduced one or two mutations. Two thirds of the genes expressed protein and six of the tested proteins gave crystals (Table 1).

Our results demonstrate that an insertion and simultaneous deletion of long fragments of DNA occurs precisely as long as the DNA polymerase used in the linear amplification reaction does not have strand displacement activity. We found that PfuTurbo ${ }^{\mathrm{TM}}$ is the preferred DNA polymerase, which implies that the length of the construct is limited to about $15 \mathrm{kbp}$ (Stratagene PfuTurbo ${ }^{\mathrm{TM}}$ manual). Although KOD (hotstart) DNA polymerase is superior in amplifying long stretches of DNA in a short time, the likelihood of strand invasion resulting in an insertion following the primer sequence is rather high (data not shown). However, the high processivity of KOD polymerase might be useful for very long constructs.

In contrast to other methods that rely on DNA amplification, the method described here does not need the subsequent cloning of the amplified gene, since the complete vector is elongated but not re-amplified. The error rate is similar to that of conventional PCR-based cloning. The validity of the approach is revealed by sequencing the cloned gene (Table 1) as well as by testing for protein expression (Fig. 2). Occasional mistakes in the primers do occur and in some rare cases strand displacement activity of PfuTurbo ${ }^{\mathrm{TM}}$ has introduced unwanted insertions (data not shown). Once PfuTurbo ${ }^{\mathrm{TM}}$ displaces the primer and continues amplifying, the product will have priming sites at both ends, resulting in exponential amplification (PCR) of the undesired product. To reduce the chance of strand displacement fewer cycles might be 
A

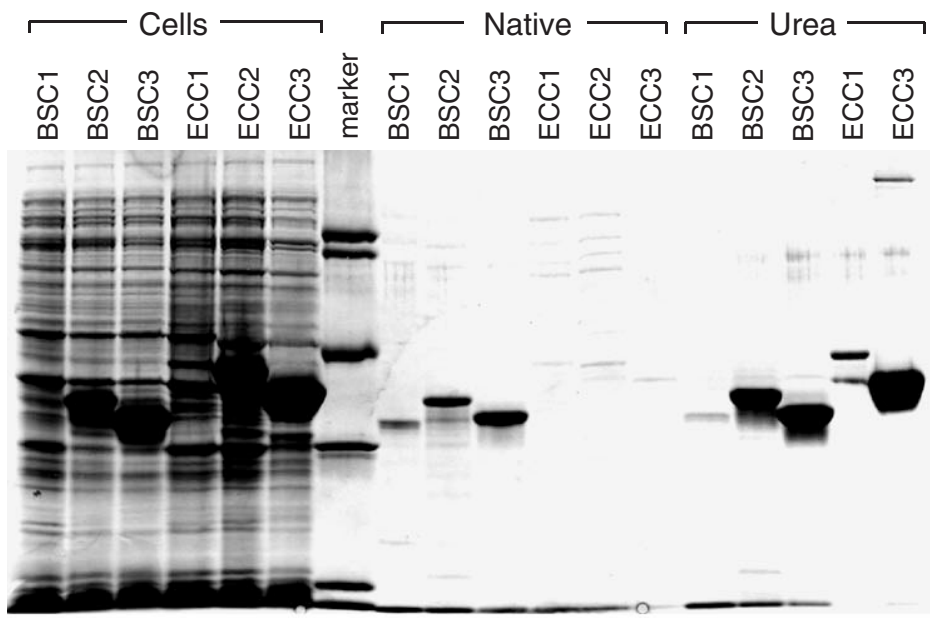

B

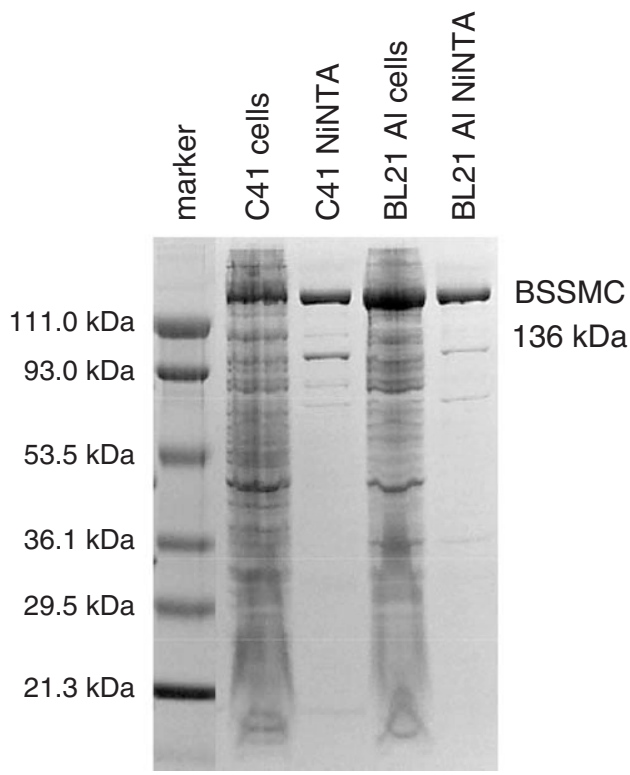

Fig. 2. Protein expression and solubility tests. A. Once transformed to BAI cells, protein expression was tested in $10 \mathrm{ml}$ cultures at $37{ }^{\circ} \mathrm{C}$, from which an aliquot was ran on a gel (lanes $\left.1-6\right)$. The proteins were purified over a Ni ${ }^{2+}-\mathrm{NTA}$ spin column (Qiagen) under native (lanes 8-13) and denatured (8 M urea) conditions (lanes 14-18). The eluate was analysed on a $12.5 \%$ SDS gel (Biorad). The marker lane contains proteins of 78, 66, 42, 30, 17 and $12 \mathrm{kDa}$. B. Test expression of the $136 \mathrm{kDa} \mathrm{BSSMC}$ protein at $25^{\circ} \mathrm{C}$ in $\mathrm{C} 41$ cells (lane 2) and BAI cells (lanes 4). The protein was purified over a NiNTA spin column under native conditions (lanes 3 and 5) and separated on a 10-20\% gradient gel.

beneficial. For the majority of clones, strand displacement was not a problem even if the number of cycles in the linear amplification reaction was 35 to improve yield. The chances of success increase by keeping the template DNA concentration to a minimum and by treating the reaction with $10 \% \mathrm{DpnI}$ for a longer period of time. This increase in $\mathrm{DpnI}$ concentration and 
the extension of time not only fully digests the double stranded methylated template DNA but also enhances digestion of hemimethylated DNA formed through pairing of the template and product DNA.

Although RF cloning provides much more freedom in choice of vectors than previous cloning methods, there are two limitations. One is the total length of the construct and the other the need to isolate the parental vector from a $\mathrm{dam}^{+}$strain. Of course other ways of eliminating the parental vector from the new product could be used, such as those described by Refs. [10,11] or by isolating the plasmid from a $d u t^{-}-u n g^{-} E$. coli strain that replaces thymidine with dUTP. Once the linear amplification reaction is completed, the parental vector containing uracil bases is selectively digested by uracil $N$-glycosylase. A different way to discriminate against the parental plasmid is by using a second mutagenic primer that repairs a defect antibiotic marker in the plasmid, in the assumption that if one set of primers will be incorporated, the second primer pair will be included as well. However, both options complicate the procedure and we believe they are unnecessary in light of the high efficiency of $D p n I$ digestion. RF cloning simplifies complex cloning procedures where long stretches of DNA can be inserted into any circular plasmid in an unrestricted way. Furthermore, it is independent of the existence of restrictions sites or even the knowledge of the entire sequence, which might make it suitable for the construction of cDNA libraries. Previously, insertions of long linkers into a specific location were difficult but is now straightforward without the need to subclone. The simplicity of both the primer design and the procedure itself makes the method suitable for high-throughput cloning since alterations to either the gene of interest or the vector are unnecessary. This has the implication that the protein of interest is expressed without the addition of extra residues coming from the cloning procedure, thus making it very attractive for structural genomics.

Protocol

5-10 $\mu$ l template $(5 \mathrm{ng} / \mu \mathrm{l})$

2-4 $\mu$ l PCR $(100 \mathrm{ng} / \mu \mathrm{l})$

$1 \mu \mathrm{dNTP}(10 \mathrm{mM})$

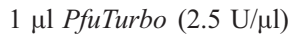

$5 \mu 110 \times$ reaction buffer

Water up to $50 \mu \mathrm{l}$
Linear amplification reaction

1. $95{ }^{\circ} \mathrm{C} 30 \mathrm{~s}$

2. $95{ }^{\circ} \mathrm{C} 30 \mathrm{~s}$

3. $55^{\circ} \mathrm{C} 1 \mathrm{~min}$

4. $68{ }^{\circ} \mathrm{C} 2 \mathrm{~min} / \mathrm{kb}$

5. GOTO 2 repeat 35 cycles

8. Hold $4^{\circ} \mathrm{C}$

\section{References}

[1] Felfoldi F, Kupihar Z, Bottka S, Puskas LG. Direct ligation of human CD4 polymerase chain reaction fragment into vectors at specific restriction sites with positional heterostagger cloning. Anal Biochem 1997;253:275-7.

[2] Zhou MY, Gomez-Sanchez CE. Universal TA cloning. Curr Issues Mol Biol 2000;2:1-7.

[3] Rashtchian A, Buchman GW, Schuster DM, Berninger MS. Uracil DNA glycosylase-mediated cloning of polymerase chain reaction-amplified DNA: application to genomic and cDNA cloning. Anal Biochem 1992;206:91-7.

[4] Aslanidis C, Dejong PJ. Ligation-independent cloning of PCR products (Lic-PCR). Nucleic Acids Res 1990;18: $6069-74$.

[5] Tillett D, Neilan BA. Enzyme-free cloning: a rapid method to clone PCR products independent of vector restriction enzyme sites. Nucleic Acids Res 1999;27:e26.

[6] Li C, Evans RM. Ligation independent cloning irrespective of restriction site compatibility. Nucleic Acids Res 1997;25:4165-6.

[7] Gibson TJ. PhD thesis. Cambridge, UK. 1984.

[8] Miroux B, Walker JE. Over-production of proteins in Escherichia coli: mutant hosts that allow synthesis of some membrane proteins and globular proteins at high levels. J Mol Biol 1996;260:289-98.

[9] Geiser M, Cebe R, Drewello D, Schmitz R. Integration of PCR fragments at any specific site within cloning vectors without the use of restriction enzymes and DNA ligase. Biotechniques 2001;31(88-90):92. 
[10] Sugimoto M, Esaki N, Tanaka H, Soda K. A simple and efficient method for the oligonucleotide-directed mutagenesis using plasmid DNA template and phosphorothioate-modified nucleotide. Anal Biochem 1989; 179:309-11.

[11] Vandeyar MA, Weiner MP, Hutton CJ, Batt CA. A simple and rapid method for the selection of oligodeoxynucleotide-directed mutants. Gene 1988;65:129-33. 